\title{
Firearm purchasing during the beginning of the COVID-19 pandemic in households with teens: a national study
}

\author{
Rebeccah L. Sokol ${ }^{1}$ • Marc A. Zimmerman ${ }^{2,3} \cdot$ Laney Rupp $^{2,3} \cdot$ Justin E. Heinze $^{2}$ • \\ Rebecca M. Cunningham ${ }^{3,4} \cdot$ Patrick M. Carter ${ }^{2,3,4}$
}

Received: 2 March 2021 / Accepted: 28 June 2021 / Published online: 9 July 2021

(C) The Author(s), under exclusive licence to Springer Science+Business Media, LLC, part of Springer Nature 2021

\begin{abstract}
To describe and identify the correlates of firearm purchasing at the beginning of the COVID-19 pandemic among US families with teenagers. In June-July 2020, we conducted a national survey of 2924 parents and their teenagers in the US. We report results from this survey to describe firearm purchasing behaviors following the start of the COVID-19 pandemic and investigate correlates of purchasing. Between the beginning of the pandemic and July $2020,10 \%$ of households with teenagers purchased a firearm, and 3\% became first-time firearm-owning households. Among firearm-owning households, firearm storage was associated with purchasing such that households that stored at least one firearm loaded and unlocked were more likely to purchase a firearm (OR: 2.02[1.07-3.79]) compared to households that stored all firearms unloaded and/or locked. Firearms purchased at the beginning of the pandemic were more likely to go to homes where at least one firearm was stored loaded and unlocked, which may contribute to increased risk for teen firearm injury and death.
\end{abstract}

Keywords Firearms · COVID-19 - National survey

Rebeccah L. Sokol

rlsokol@wayne.edu

1 School of Social Work, Wayne State University, 5447 Woodward Ave, Detroit, MI 48202, USA

2 Department of Health Behavior and Health Education, School of Public Health, University of Michigan, 1415 Washington Heights, Ann Arbor, MI 48109-2029, USA

3 University of Michigan Injury Prevention Center, 2800 Plymouth Road, NCRC 10-G080, Ann Arbor, MI 48109, USA

4 Department of Emergency Medicine, University of Michigan School of Medicine, 1500 East Medical Center Drive, Ann Arbor, MI 48109, USA

\section{Introduction}

Prior to the coronavirus disease 2019 (COVID-19) pandemic, around one-third of parents in the United States kept a gun in or around their homes (Azrael et al., 2018; D. Hamilton et al., 2018a, b). Firearm purchases have been increasing since the 1990s (Liu \& Wiebe, 2019), but estimates suggest 2.1 million excess firearms were purchased in the first few months of the COVID-19 pandemic-a $64.3 \%$ increase over expected volume (Schleimer et al., 2020). More specifically, spikes in background checks occurred immediately following the onset of the COVID-19 shut-downs in the United States (March 2020) and during nationwide protests following the murder of George Floyd (June 2020) (Lang \& Lang, 2021). Increased firearm access during a time when social isolation and stress are high has the potential to increase suicide rates (Mannix et al., 2020; Papadimos, 2020; Reger et al., 2020) and violence (Campbell, 2020; Schleimer et al., 2020; Usher et al., 2020), with some analyses suggesting the increased number of firearms in homes at the beginning of the pandemic resulted in increased violence (Schleimer et al., 2020).

Although we know firearm sales have increased, we know relatively little regarding the correlates of this rise in purchasing, particularly among parents of teenagers (defined presently as children ages $14-18$ years old). It is especially important to assess the presence of firearms within the homes of teenagers, as this group has some of the highest rates of fatal and non-fatal firearm injuries of any age group (WISQARS, 2019a, b), and firearms are a leading cause of death among young people (Cunningham et al., 2018). Annually, the teen firearm injury rate for 14-18 year-olds is around 48 per 100,000 teens, and the firearm death rate is around 10.5 per 100,000 teens (WISQARS, 2019a, b). Identifying the conditions underlying firearm purchases is 
an important step towards understanding the corresponding teen health and safety implications of this increased number of firearms in homes.

Firearm sales rise following mass shootings, acts of terror, and political uncertainty surrounding future gun policy (Depetris-Chauvin, 2015; Lang \& Lang, 2020, 2021). Specifically, researchers have found that both perceptions of decreased personal safety (Depew \& Swensen, 2019; Lang $\&$ Lang, 2021) and future gun policy uncertainty (DepetrisChauvin, 2015; Lang \& Lang, 2021) can lead to more firearm purchases. The specific conditions under which a firearm is purchased-including parents' violence exposure, parents' and teens' mental health status, and household firearm storage practices-have implications for public health messaging, firearm legislation, and community and clinical interventions focused on preventing firearm violence.

\section{Violence exposure}

Interpersonal and community violence exposure has continued throughout the pandemic and may be on the rise (Boserup et al., 2020; Humphreys et al., 2020; Mazza et al., 2020). Thus, assessing violence exposure as a correlate of firearm purchasing may provide insights as to the circumstances under which firearms entered homes during the pandemic. Researchers previously found that young parents in urban settings who purchase firearms for protection against potential violence are more likely to store firearms loaded and/ or unlocked compared to parents who purchase for other motivations (Sokol et al., 2020). Extending these findings, parents with high levels of perceived violence exposure who purchase a firearm may be more likely to store firearms in an accessible manner that increases risk for teen firearm injury, but we have yet to assess the relationship between violence exposure and firearm purchasing among parents in the general population. If violence exposure is correlated with firearm purchasing among parents during this time, efforts to reduce violence exposure, including both community-level (Branas et al., 2018; Heinze et al., 2018) and individual-level violence prevention interventions (Carter et al., 2016; Walton et al., 2010), may encourage parents to store purchased firearms in a less accessible manner (i.e., unloaded and/or locked) or reduce firearm purchasing altogether.

\section{Mental health}

During the beginning of the pandemic, adults reported elevated adverse mental health conditions, including suicide ideation (Czeisler et al., 2020). Although researchers have not previously found a relationship between mental health status and firearm ownership (Morgan et al., 2018; Sorenson \& Vittes, 2008), this relationship has not been evaluated in the context of a pandemic. A correlation between experiencing mental health distress and firearm purchasing would suggest the need for more widespread implementation of firearm-related policies that are associated with reduced suicide rates, such as mandatory waiting periods for completing firearm purchases, universal background checks before acquiring a handgun, gun lock requirements, and open carrying regulation (Anestis \& Anestis, 2015; Anestis et al., 2017).

\section{Firearm storage}

Finally, firearm storage is an important factor to consider in homes with recently purchased firearms, as firearms that are more easily accessible (i.e., loaded and unlocked) increase child and youth risk of unintentional and intentional injury and death (Miller et al., 2005; Monuteaux et al., 2019). Teen suicide is of particular concern following the start of the COVID-19 pandemic. Given that adolescent and young adult depression, anxiety, suicide ideation, and suicide attempts increased following the start of the COVID-19 pandemic (Hawes et al., 2021; Hill et al., 2021), it is important to consider firearm access among teens. In $75 \%$ of teen firearm suicides, teens access the firearm either in their own home or the home of a relative (Grossman et al., 2005; Johnson et al., 2010). Thus, newly purchased firearms could increase risk of teen suicide, especially if firearms are stored in an accessible manner. If newly purchased firearms are going to homes where firearms are stored loaded and unlocked, the implementation of strong child access prevention (CAP) laws could promote safe firearm storage-and decrease risk of firearm injury and death-by imposing criminal liability on adults who allow children access to firearms (Hamilton et al., 2018a, b).

The overall goals of this paper are to: (1) Report results from the FACTS national survey of 2924 parents of teenagers in the United States that describes the firearm purchasing behaviors following the start of the COVID-19 pandemic; and (2) Investigate the correlates of this firearm purchasing.

\section{Methods}

\section{Data}

In June and July 2020, the study team conducted the FACTS National Survey, which was a cross-sectional, web-based, survey of 2924 U.S. parents and their teens (ages 14-18 years) regarding firearm-related practices. We defined parents as the primary caretakers of teens (e.g., parent, step-parent, grandparent; hereafter referred to as 'parent'). Parent participants for the study were parents from the Gallup Panel, a probability-based panel that is constructed to be broadly representative of the U.S. adult population. 
The Gallup Panel recruits panel members using randomdigit phone dialing that covers landline and cell phones and address-based sampling methods. Gallup's recruiting efforts oversample adults between the ages of 18 and 34, individuals with lower education levels, and members of racial and ethnic minority groups. After providing informed consent, parent panel participants and their teens were asked to complete a confidential web-based written survey for the present study. Participants received $\$ 5$ for completing the online survey. Panel weights assigned to each respondent incorporated unequal selection probabilities to make analyses nationally representative of parents of teens. The University of Michigan Institutional Review Board approved this study. We used the parent and teen responses to describe how firearm purchasing changed following the COVID-19 pandemic, and how these changes correlate to demographic characteristics, violence exposure, mental health, and firearm storage behaviors.

\section{Measures}

\section{Household firearm ownership}

To identify if someone within the household owned a gun, we asked all parents: "Do you personally own a gun?" and "Does anyone else you live with own a gun?" Responding yes to either question was indicative of household firearm ownership.

\section{Firearm purchasing}

To assess if an additional firearm entered the household since the start of the COVID-19 pandemic, we asked parents: "Since the start of the COVID-19 pandemic, have you or someone in your home purchased a gun?" Responding yes to this question was indicative of the household purchasing a firearm since the start of the pandemic —our primary outcome variable. If parents indicated that they or a household member had purchased a firearm, to assess if this firearm purchase was the first firearm to enter the household we further asked: "Was this gun the first gun that someone in your household has purchased?"

\section{Violence exposure}

Parents' violence exposure comprised two variables: nonpartner victimization and community violence exposure. We operationalized parents' non-partner violence victimization as the sum of three seven-point Likert items adapted from the physical assault domain of the revised Conflict Tactics Scale (CTS2; Straus et al., 1996). The original CTS2 physical assault domain includes twelve items and exhibits high internal consistency reliability $(\alpha=0.86)$. For item parsimony, we combined the behaviors from the twelve items into three items. The three items asked, "In the past 12 months, how many times has a friend, neighbor, coworker, or stranger done any of the following TO YOU during any fights, conflicts, arguments or physical attacks?: (1) Twisted your arm, thrown something that could hurt you, pushed, shoved, grabbed, slapped, or slammed you against a wall?; (2) Kicked, bit, or hit you, beat you up, choked you, threatened you with a knife or used a knife on you?; (3) Threatened you with a gun or used a gun on you (e.g., shot at or around you)?" Response options ranged from the physical assault event never occurring (1) to occurring more than 20 times (7), for a total score ranging from 3 to 21 .

We operationalized parents' community violence exposure as the sum of nine dichotomous items from the Things I Have Seen and Heard survey (range 0-9) (Richters \& Saltzman, 1990). Originally a 15 -item scale, we restricted the survey to the following items to focus on more serious violent behaviors, asking "In the past 12 months, which of the following things have you seen or heard in your neighborhood: (1) I have heard guns being shot; (2) I have seen somebody arrested; (3) I have seen drug deals; (4) I have seen somebody get beaten up; (5) I have seen somebody get stabbed; (6) I have seen somebody pull a knife on another person; (7) I have seen somebody pull a gun on another person; (8) I have seen somebody get shot; (9) My house has been broken into."

\section{Mental health status}

Mental health status encompassed two separate variables for both parents and teens, each: depression and perceptions of change in mental health status during the pandemic. We measured depression among parents and teens using a twoitem depression screener (PHQ-2), with scores greater than or equal to three indicative of depression (scores less than three indicated the absence of depression) (Kroenke et al., 2003). We measured mental health status during the pandemic by asking parents and their teens: "Since the start of the COVID-19 pandemic, my overall mental health is...", with responses ranging from "much improved" (1) to "much worse" (5).

\section{Unsafe firearm storage}

Among firearm-owning households, we asked parents if any of the firearms that parents personally own and keep on their property are stored both loaded and unlocked. Specifically, we asked parents who reported owning long guns: "Are any of the long guns on your property stored both loaded and unlocked?" We asked parents who reported owning handguns: "Are any of the handguns on your property stored both loaded and unlocked?" Responding yes to either question 
was indicative of practicing unsafe firearm storage. We asked firearm storage questions only among respondents reporting they personally owned a firearm (rather than only someone in the household owning a firearm), as researchers have previously established that reports of firearm storage practices differ between personal and household-only owners (Azrael et al., 2000). We imputed firearm storage practice values for the $19 \%$ of the sample that reported household-only firearm ownership, as described below in the Analysis section.

We defined unsafe firearm storage as storing a firearm both loaded and unlocked, as evidence suggests this method of dual-ease-of-access is most highly associated with risk for firearm injury and death (Miller et al., 2005). Because storing a firearm loaded or unlocked is also associated with firearm injury and death (Brent et al., 1993; Monuteaux et al., 2019), we conducted a sensitivity analysis that defined unsafe storage as storing at least one firearm loaded and/or unlocked.

\section{Demographic characteristics}

We collected demographic variables including parent: biological sex, age, education, race, ethnicity, and geographic region (based on U.S. census region).

\section{Analysis}

We investigated the correlates of firearm purchasing through a series of multivariable logistic regressions using RStudio ${ }^{\circledR}$ statistical software. To account for missing data, we imputed ten datasets using a bootstrap-based Expectation Maximization with Bootstrapping (EMB) algorithm (Honaker et al., 2011) and pooled results over the imputed datasets. We weighted all descriptive statistics and analyses to be nationally representative of parents of teenage children.

We conducted multivariable logistic regression analyses among: (1) all households $(\mathrm{n}=2924)$, and (2) households where a parent indicated they (or someone in their home) owned a firearm $(n=1452)$. The outcome for all models was if the parent/someone in the home had purchased a firearm since the start of the COVID-19 pandemic (e.g., yes or no). Given previous research showing ownership differences by demographic characteristics (Geier et al., 2017; D. Hamilton et al., 2018a, b; Monuteaux et al., 2015), we included parent sex, age, education, race, and US census region as baseline model covariates. We then added potential correlates of firearm purchasing in a step-wise manner. Among our sample of all households and sub-sample of firearmowning households, this second correlate set included risk factors for firearm injury and violence, namely parents' violence exposure and parents' and teens' mental health status and mental health perceptions. Among our sub-sample of firearm-owning households, we included a third correlate set of unsafe firearm storage practices in the household.

\section{Results}

Table 1 provides descriptive statistics for our sample and sub-sample. Among all households with teenagers (age 14-18) in the United States, $10 \%$ purchased a firearm between the start of the COVID-19 pandemic and July 2020 and 3\% became first-time firearm-owning households.

In our first series of multivariable logistic regression models that assessed firearm purchasing since the start of the pandemic among all households with teenagers, including risk factors for firearm injury and violence (i.e., parents' violence exposure and parents' and teens' mental health status/perceptions) did not improve model fit (Wald Test: $\chi 2(12)=1.32, p=0.20)$. Thus, our baseline model of demographic correlates became the final model of firearm purchasing correlates for all parents (Table 2, Model 1, left panel). Geographic region was associated with firearm purchasing, such that households in the Midwest (OR: 2.32, 95\% CI $[1.21,4.46])$ and South (OR: 2.68, 95\% CI [1.47, 4.90]) were more likely to purchase a firearm compared to parents living in the West, and parents living in the Northeast were less likely to purchase a firearm compared to parents living in the West (OR: 0.36, 95\% CI [0.17, 0.74]). Parent education was also associated with firearm purchasing, such that households with parents who attained a high school education or less (OR: 2.33, 95\% CI [1.19, 4.58]) and some college or trade training (OR: $1.84,95 \%$ CI [1.07, 3.18]) were more likely to purchase a firearm compared to parents who attained post-graduate education.

In our second series of multivariable logistic regression models assessing firearm purchasing since the start of the pandemic among firearm-owning households, including firearm injury and violence risk factors did not improve model fit (Wald Test: $\chi 2(12)=1.48, p=0.12$ ). Including unsafe firearm storage in the multivariable logistic model did improve model fit (Wald Test: $\chi 2(1)=4.80, p=0.03$ ), thus we retained this firearm storage correlate set in the final model, along with demographic control variables (Table 2, Model 3). Geographic region was associated with firearm purchasing, such that firearm-owning households living in the Midwest (OR: 2.63, 95\% CI $[1.27,5.46])$ and South (OR: $2.22,95 \%$ CI $[1.14,4.31])$ were more likely to purchase a firearm compared to parents living in the West. Firearm storage was also associated with firearm purchasing within firearm-owning households, whereby households that practiced unsafe firearm storage (e.g., at least one firearm loaded and unlocked) were more likely to purchase a firearm (OR: $2.02,95 \%$ CI [1.07-3.79]) since the start of the pandemic compared to households who practiced safe firearm storage. 
Table 1 Descriptive statistics for the analytic samples of parents of teenage children

Mean (se) or percentage

All parents $(\mathrm{n}=2924)$

$10 \%$
$3 \%$

Household purchase of a firearm since the start of the pandemic

First-time firearm-owning household

Demographic factors

Age

Biological sex

Male

Female

Education

Less than high school/high school

Some college/trade school

College graduate

Post-graduate schooling

Race/ethnicity

Non-Hispanic White

Non-Hispanic Black

Non-Hispanic Asian

Hispanic

Other race

Geographic region

Northeast

Midwest

South

West

Firearm injury/violence risk factors

Positive depression screen: Parent

Positive depression screen: Teen

Perceptions of mental health status since the start of the pandemic: Parent

Much improved

Slightly improved

Stayed the same

Slightly worse

Much worse

Perceptions of mental health status since the start of the pandemic: Teen

Much improved

Slightly improved

Stayed the same

Slightly worse

Much worse

Community violence exposure

Non-partner violence victimization

Firearm storage behaviors

All firearms unloaded and/or locked

$\geq 1$ firearm loaded and unlocked

All firearms unloaded and locked

$\geq 1$ firearm loaded and/or unlocked
$18 \%$

$5 \%$

$47.5(0.36)$

$47.0(0.50)$

$45 \%$

$55 \%$

$52 \%$

owning parents

$(\mathrm{n}=1452)$

$29 \%$

$33 \%$

$31 \%$

$33 \%$

$17 \%$

$16 \%$

$23 \%$

$18 \%$

$74 \%$

$79 \%$

$12 \%$

$10 \%$

$1 \%$

$<1 \%$

$13 \%$

$11 \%$

$<1 \%$

$<1 \%$

$16 \%$

$10 \%$

$22 \%$

$22 \%$

$37 \%$

$42 \%$

$25 \%$

$26 \%$

$9 \%$

9\%

$14 \%$

$14 \%$

$3 \%$

$4 \%$

$8 \%$

$7 \%$

$58 \%$

$67 \%$

$28 \%$

$19 \%$

$3 \%$

$3 \%$

$3 \%-3 \%$

$9 \% \quad 9 \%$

$56 \% \quad 61 \%$

$27 \% \quad 24 \%$

$5 \% \quad 3 \%$

$0.85(0.05) \quad 0.88(0.07)$

$3.05(0.02) \quad 3.06(0.03)$

\begin{tabular}{ll}
- & $75 \%$ \\
- & $25 \%$ \\
- & $33 \%$ \\
- & $67 \%$ \\
\hline
\end{tabular}

Estimates pooled across ten imputed datasets and weighted to be nationally representative of parents of teenagers in the United States 
Table 2 Odds ratios for correlates of household purchase of a firearm between the start of the COVID-19 pandemic and July 2020 for all households $(n=2924)$ and for firearm-owning households $(n=1452)$

\begin{tabular}{|c|c|c|c|c|c|}
\hline & \multicolumn{2}{|c|}{ Model 1: Demographic factors } & \multicolumn{2}{|c|}{$\begin{array}{l}\text { Model 2: Demographic factors + firearm injury/vio- } \\
\text { lence risk factors }\end{array}$} & \multirow{2}{*}{$\begin{array}{l}\text { Model 3: Demographic } \\
\text { factors + firearm storage } \\
\text { behaviors } \\
\text { Firearm-owning households }\end{array}$} \\
\hline & All households & $\begin{array}{l}\text { Firearm-owning house- } \\
\text { holds }\end{array}$ & All households & $\begin{array}{l}\text { Firearm-owning house- } \\
\text { holds }\end{array}$ & \\
\hline \multicolumn{6}{|l|}{ Demographic factors } \\
\hline Age & $0.99(0.96,1.01)$ & $0.99(0.96,1.02)$ & $0.99(0.96,1.01)$ & $0.99(0.96,1.02)$ & $0.99(0.96,1.02)$ \\
\hline \multicolumn{6}{|c|}{ Biological sex (Reference: female) } \\
\hline Male & $1.16(0.71,1.89)$ & $0.87(0.52,1.46)$ & $1.05(0.62,1.77)$ & $0.82(0.48,1.41)$ & $0.83(0.49,1.40)$ \\
\hline \multicolumn{6}{|c|}{ Education (Reference: post-graduate education) } \\
\hline $\begin{array}{l}\text { Less than high school/ } \\
\text { high school }\end{array}$ & $2.33(1.19,4.58)^{*}$ & $1.94(0.98,3.87)$ & $1.70(0.82,3.54)$ & $1.53(0.74,3.15)$ & $1.80(0.95,3.85)$ \\
\hline $\begin{array}{l}\text { Some college/trade } \\
\text { school }\end{array}$ & $1.84(1.07,3.18)^{*}$ & $1.51(0.86,2.66)$ & $1.47(0.81,2.65)$ & $1.22(0.66,2.25)$ & $1.55(0.88,2.73)$ \\
\hline College graduate & $0.83(0.42,1.64)$ & $0.71(0.35,1.41)$ & $0.77(0.38,1.59)$ & $0.63(0.31,1.30)$ & $0.72(0.36,1.46)$ \\
\hline \multicolumn{6}{|c|}{ Race/ethnicity (Reference non-hispanic white) } \\
\hline Non-hispanic black & $1.36(0.62,1.98)$ & $1.73(0.76,3.95)$ & $1.10(0.46,2.64)$ & $1.64(0.65,4.14)$ & $1.85(0.80,4.25)$ \\
\hline Non-hispanic Asian & $0.67(0.03,15.94)$ & $2.50(0.40,15.71)$ & $0.81(0.01,62.2)$ & $2.33(0.27,19.82)$ & $3.16(0.59,16.81)$ \\
\hline Hispanic & $0.80(0.34,1.87$ & $0.87(0.34,2.21)$ & $0.59(0.25,1.42)$ & $0.70(0.26,1.92)$ & $0.95(0.36,2.47)$ \\
\hline Other race & - & - & - & - & - \\
\hline \multicolumn{6}{|c|}{ Geographic region (Reference: West) } \\
\hline Northeast & $0.36(0.17,0.74)^{*}$ & $0.54(0.24,1.22)$ & $0.40(0.19,1.83)$ & $0.63(0.28,1.45)$ & $0.53(0.23,1.22)$ \\
\hline Midwest & $2.32(1.21,4.46)^{*}$ & $2.67(1.32,5.41)^{*}$ & $2.58(1.37,4.86)^{*}$ & $2.97(1.46,6.04)^{*}$ & $2.63(1.27,5.46)^{*}$ \\
\hline South & $2.68(1.47,4.90)^{*}$ & $2.57(1.34,4.92)^{*}$ & $2.89(1.61,5.19)^{*}$ & $2.83(1.49,5.39)^{*}$ & $2.22(1.14,4.31)^{*}$ \\
\hline \multicolumn{6}{|c|}{ Firearm injury/violence risk factors } \\
\hline $\begin{array}{l}\text { Positive depression } \\
\text { screen: Parent }\end{array}$ & - & - & $2.15(0.82,5.63)$ & $2.34(0.74,7.39)$ & - \\
\hline $\begin{array}{l}\text { Positive depression } \\
\text { screen: Teen }\end{array}$ & - & - & $1.00(0.34,2.92)$ & $0.84(0.29,2.45)$ & \\
\hline $\begin{array}{l}\text { Perceptions of mental } \\
\text { health since the start } \\
\text { of the pandemic } \\
\text { (Reference: Same): } \\
\text { Parent }\end{array}$ & - & - & & & - \\
\hline Much worse & - & - & $0.97(0.27,3.41)$ & $0.93(0.19,4.41)$ & - \\
\hline Slightly worse & - & - & $0.43(0.20,0.92)^{*}$ & $0.77(0.35,1.68)$ & - \\
\hline Slightly better & - & - & $0.53(0.23,1.22)$ & $0.78(0.33,1.87)$ & - \\
\hline Much better & - & - & $0.39(0.07,2.09)$ & $0.28(0.05,1.64)$ & - \\
\hline $\begin{array}{l}\text { Perceptions of mental } \\
\text { health since the start } \\
\text { of the pandemic (Ref- } \\
\text { erence: same): Teen }\end{array}$ & - & - & & & \\
\hline Much worse & - & - & $0.64(0.10,4.19)$ & $0.84(0.19,3.68)$ & \\
\hline Slightly worse & - & - & $0.62(0.32,1.22)$ & $0.57(0.25,1.20)$ & \\
\hline Slightly better & - & - & $0.27(0.05,1.57)$ & $0.29(0.09,0.98)$ & \\
\hline Much better & - & - & $0.79(0.11,5.86)$ & $1.08(0.18,6.57)$ & \\
\hline $\begin{array}{l}\text { Community violence } \\
\text { exposure }\end{array}$ & - & - & $1.14(0.95,1.37)$ & $1.16(0.96,1.40)$ & - \\
\hline $\begin{array}{l}\text { Non-partner violence } \\
\text { victimization }\end{array}$ & - & - & $1.22(0.74,2.01)$ & $1.15(0.72,1.82)$ & - \\
\hline \multicolumn{6}{|l|}{ Firearm storage behaviors } \\
\hline $\begin{array}{l}\geq 1 \text { firearm loaded and } \\
\text { unlocked (Reference: } \\
\text { All firearms unloaded } \\
\text { and/or locked) }\end{array}$ & - & - & - & - & $2.02(1.07,3.79)^{*}$ \\
\hline Wald test & - & - & $\chi^{2}(12)=1.32, p=0.20$ & $\chi 2(12)=1.48, p=0.12$ & $\chi 2(1)=4.80, p=0.03$ \\
\hline
\end{tabular}

*indicates $p<0.05$. Estimates pooled across ten imputed datasets and weighted to be nationally representative of parents of teenagers in the United States. Odds ratios for non-Hispanic other race not shown, as sample sizes were small and produced unreliable odds ratio estimate 
In our sensitivity analyses, unsafe storage defined as storing at least one firearm loaded and/or unlocked was not associated with purchasing a firearm during the beginning of the pandemic (OR: $1.02 ; 95 \%$ CI $[0.54,1.91])$.

\section{Discussion}

Firearm purchases rose at the start of the COVID-19 pandemic, including among parents, and a notable percentage of households with teens have become first-time firearmowning households during this time. Such purchases are concerning because, as we found, these firearms were more likely to end up in a home with teens present where at least some firearms are stored loaded and unlocked compared to homes where all firearms are stored unloaded and/or locked. The risk of child or youth firearm injury and death is substantially higher in homes where a firearm is present (Branas et al., 2009; Dahlberg et al., 2004; Monuteaux et al., 2019), and in homes where a firearm is present, risk of child or youth firearm injury and death is higher yet when a firearm is stored loaded and unlocked (Branas et al., 2009; Dahlberg et al., 2004; Miller et al., 2005; Monuteaux et al., 2019). Safe storage has been central to preventing firearm-related injuries and death among children and youth (Monuteaux et al., 2019), and the need for strategies that promote safe storage appears to be heightened after the onset of the COVID-19 pandemic.

Parents' and teens' mental health status and perceptions of change in mental health were not associated with firearm purchasing. This finding aligns with multiple prior studies indicating no relationship between mental health status and firearm ownership (Morgan et al., 2018; Sorenson \& Vittes, 2008). Although parent and teen mental health statuses are not driving firearm purchasing at a population level, we found that around one in seven households that purchased a firearm during the beginning of the COVID-19 pandemic had a teen that screened positive for depression. Thus, firearm purchasing is co-occurring with teen depression. Researchers have found that adolescent and young adult suicide ideation and attempts increased during the beginning of the COVID-19 pandemic in some sample populations (Hill et al., 2021). Because firearm availability increases risk for injury and death, including suicide (Miller et al., 2007; Monuteaux et al., 2019; Morgan et al., 2018; Schleimer et al., 2020), the influx of firearms into homes during a time when teen suicidality may be heightened could increase risk of teen suicide. Clinical interventions, such as lethal means screening and counseling, are promising strategies to reduce teen suicide risk for the duration of the COVID-19 pandemic and beyond (Bandealy et al., 2020; Mann et al., 2005).

From our sensitivity analyses, it appears that only the households storing at least one firearm in the most accessible and unsafe manner (i.e., loaded and unlocked) were more likely to purchase a firearm during the beginning of the pandemic (compared to households where all firearms were stored unloaded and/or locked). Households that stored at least one firearm only loaded and/or unlocked were no more likely to purchase a firearm during the beginning of the pandemic compared to firearm-owning households that stored all firearms both unloaded and locked. Given the relative ease-of-access to firearms stored loaded and unlocked, the entry of firearms into homes where this firearm storage practice occurs may increase the risk of teen firearm injury and death.

Harm reduction strategies that focus on encouraging parents to move incrementally towards safer storage options may help reduce risk of firearm injury or death. The implementation of strong child access prevention (CAP) laws, for example, could promote safer firearm storage (Hamilton et al., 2018a, b). Such laws might encourage parents who store firearms loaded and unlocked to store them locked, unloaded, or both locked and unloaded (Prickett et al., 2014). To significantly reduce child and youth injury and death rates, researchers have found that such CAP laws need to impose criminal liability when a child gains access to a negligently stored firearm, rather than only imposing criminal liability when an adult intentionally, knowingly, or recklessly provides a firearm to a child (Hamilton et al., 2018a, b).

Our nationally representative sample of parents of teenage children may not generalize to all US adults or parents of all aged children. While the use of self-report questions raises the potential for social desirability and recall bias, prior research has identified that the use of self-report measures has high reliability and validity when confidentiality is assured (Brener et al., 2003). Researchers have also found, however, that self-reports of household firearm ownership are reported differently between men and women, and between firearm-users and non-users (Azrael et al., 2000). To confront these potential sources of bias, we controlled for biological sex in analyses, and we asked only personal firearm owners about firearm storage. An additional limitation of the present analyses involves our inability to infer causation; we do not know that the COVID-19 pandemic is causing changes in firearm purchases. Importantly, other national events external to the pandemic occurred during the data collection time period, including the deaths of George Floyd, Brianna Taylor, and Ahmud Arbery, and the resulting national protests against police violence and white supremacy (Barbot, 2020). Federal Bureau of Investigation data show spikes in firearm background check rates in both March 2020 (the month of COVID-19-related shutdowns in the United States) and June 2020 (the month following the murder of George Floyd), and researchers suggest both increases were due to heightened health and safety concerns 
(Lang \& Lang, 2021). It remains unclear what specific circumstances-or combination of circumstances-precipitated the changes in firearm and purchasing that we identified. Future research needs to focus on the individual- and family-level reactions to crises that might motivate firearmrelated behavior changes. Understanding the drivers of firearm purchasing, including during public health crises, may be helpful in guiding efforts to prevent unsafe firearm ownership in the future. Likewise, the implications of this line of research may extend beyond the COVID-19 pandemic.

\section{Conclusion}

Ten percent of households with of teenagers purchased a firearm during the beginning of the COVID-19 pandemic, and 3\% became first-time firearm-owning households. Firearms purchased at the beginning of the pandemic were more likely to go to homes where at least one firearm was stored loaded and unlocked, which may contribute to increased risk for teen firearm injury during this time. Public health messaging, policy initiatives, and clinical interventions that continue to promote safe firearm handling and storage practices among firearm-owning parents during and beyond the COVID-19 pandemic may reduce teen risk of firearm injury and death.

Author contributions RLS was involved in survey design, and RLS developed and led analysis and manuscript writing. MAZ, PMC, RMC, $\mathrm{JEH}$, and LR led survey design and data collection and contributed to the writing and editing of the manuscript.

Funding Data collection for this project was funded through the National Institutes of Health, National Institute of Child Health and Human Development (1R24HD087149-01A1).

\section{Declarations}

Conflict of interest The authors have no conflicts of interest to disclose.

Consent to participate Participants provided informed consent prior to completing the questionnaire.

Consent for publication Participants provided informed consent prior to completing the questionnaire.

Ethical approval The University of Michigan Institutional Review Board approved this study.

\section{References}

Anestis, M. D., \& Anestis, J. C. (2015). Suicide rates and state laws regulating access and exposure to handguns. American Journal of Public Health, 105(10), 2049-2058.

Anestis, M. D., Selby, E. A., \& Butterworth, S. E. (2017). Rising longitudinal trajectories in suicide rates: The role of firearm suicide rates and firearm legislation. Preventive Medicine, 100, 159-166.

Azrael, D., Cohen, J., Salhi, C., \& Miller, M. (2018). Firearm storage in gun-owning households with children: Results of a 2015 national survey. Journal of Urban Health, 95(3), 295-304.

Azrael, D., Miller, M., \& Hemenway, D. (2000). Are household firearms stored safely? It depends on whom you ask. Pediatrics, 106(3), e31-e31.

Bandealy, A., Herrera, N., Weissman, M., \& Scheidt, P. (2020). Use of lethal means restriction counseling for suicide prevention in pediatric primary care. Preventive Medicine, 130, 105855.

Barbot, O. (2020). George Floyd and our collective moral injury. American Journal of Public Health, 110(9), 1253-1253. https://doi.org/ 10.2105/AJPH.2020.305850

Boserup, B., McKenney, M., \& Elkbuli, A. (2020). Alarming trends in US domestic violence during the COVID-19 pandemic. The American Journal of Emergency Medicine, 38(12), 2753-2755. https:// doi.org/10.1016/j.ajem.2020.04.077

Branas, C. C., Richmond, T. S., Culhane, D. P., Ten Have, T. R., \& Wiebe, D. J. (2009). Investigating the link between gun possession and gun assault. American Journal of Public Health, 99(11), 2034-2040. https://doi.org/10.2105/AJPH.2008.143099

Branas, C. C., South, E., Kondo, M. C., Hohl, B. C., Bourgois, P., Wiebe, D. J., \& MacDonald, J. M. (2018). Citywide cluster randomized trial to restore blighted vacant land and its effects on violence, crime, and fear. Proceedings of the National Academy of Sciences, 115(12), 2946-2951. https://doi.org/10.1073/pnas.1718503115

Brener, N. D., Billy, J. O., \& Grady, W. R. (2003). Assessment of factors affecting the validity of self-reported health-risk behavior among adolescents: Evidence from the scientific literature. Journal of Adolescent Health, 33(6), 436-457.

Brent, D. A., Perper, J., Moritz, G., Baugher, M., \& Allman, C. (1993). Suicide in adolescents with no apparent psychopathology. Journal of the American Academy of Child and Adolescent Psychiatry, 32(3), 494-500.

Campbell, A. M. (2020). An increasing risk of family violence during the Covid-19 pandemic: Strengthening community collaborations to save lives. Forensic Science International: Reports., 2, 100089.

Carter, P. M., Walton, M. A., Zimmerman, M. A., Chermack, S. T., Roche, J. S., \& Cunningham, R. M. (2016). Efficacy of a universal brief intervention for violence among urban emergency department youth. Academic Emergency Medicine, 23(9), 1061-1070.

Cunningham, R. M., Walton, M. A., \& Carter, P. M. (2018). The major causes of death in children and adolescents in the United States. New England Journal of Medicine, 379(25), 2468-2475.

Czeisler, M. É., Lane, R. I., Petrosky, E., Wiley, J. F., Christensen, A., Njai, R., Weaver, M. D., Robbins, R., Facer-Childs, E. R., \& Barger, L. K. (2020). Mental health, substance use, and suicidal ideation during the COVID-19 pandemic_-United States, June 24-30, 2020. Morbidity and Mortality Weekly Report, 69(32), 1049.

Dahlberg, L. L., Ikeda, R. M., \& Kresnow, M. (2004). Guns in the home and risk of a violent death in the home: Findings from a national study. American Journal of Epidemiology, 160(10), 929-936.

Depetris-Chauvin, E. (2015). Fear of Obama: An empirical study of the demand for guns and the US 2008 presidential election. Journal of Public Economics, 130, 66-79.

Depew, B., \& Swensen, I. D. (2019). The decision to carry the effect of crime on concealed-carry applications. Journal of Human Resources, 54(4), 1121-1153. 
Geier, D. A., Kern, J. K., \& Geier, M. R. (2017). A longitudinal ecological study of household firearm ownership and firearm-related deaths in the United States from 1999 through 2014: A specific focus on gender, race, and geographic variables. Preventive Medicine Reports, 6, 329-335.

Grossman, D. C., Mueller, B. A., Riedy, C., Dowd, M. D., Villaveces, A., Prodzinski, J., Nakagawara, J., Howard, J., Thiersch, N., \& Harruff, R. (2005). Gun storage practices and risk of youth suicide and unintentional firearm injuries. JAMA, 293(6), 707-714.

Hamilton, D., Lemeshow, S., Saleska, J. L., Brewer, B., \& Strobino, K. (2018a). Who owns guns and how do they keep them? The influence of household characteristics on firearms ownership and storage practices in the United States. Preventive Medicine, 116, 134-142.

Hamilton, E. C., Miller, C. C., III., Cox, C. S., Jr., Lally, K. P., \& Austin, M. T. (2018b). Variability of child access prevention laws and pediatric firearm injuries. Journal of Trauma and Acute Care Surgery, 84(4), 613-619.

Hawes, M. T., Szenczy, A. K., Klein, D. N., Hajcak, G., \& Nelson, B. D. (2021). Increases in depression and anxiety symptoms in adolescents and young adults during the COVID-19 pandemic. Psychological Medicine. https://doi.org/10.1017/S0033291720005358

Heinze, J. E., Krusky-Morey, A., Vagi, K. J., Reischl, T. M., Franzen, S., Pruett, N. K., Cunningham, R. M., \& Zimmerman, M. A. (2018). Busy streets theory: The effects of community-engaged greening on violence. American Journal of Community Psychology, 62(1-2), 101-109.

Hill, R. M., Rufino, K., Kurian, S., Saxena, J., Saxena, K., \& Williams, L. (2021). Suicide ideation and attempts in a pediatric emergency department before and during COVID-19. Pediatrics. https://doi. org/10.1542/peds.2020-029280

Honaker, J., King, G., \& Blackwell, M. (2011). Amelia II: A program for missing data. Journal of Statistical Software, 45(7), 1-47.

Humphreys, K. L., Myint, M. T., \& Zeanah, C. H. (2020). Increased risk for family violence during the COVID-19 pandemic. Pediatrics, 146(1), e20200982. https://doi.org/10.1542/peds.2020-0982

Johnson, R. M., Barber, C., Azrael, D., Clark, D. E., \& Hemenway, D. (2010). Who are the owners of firearms used in adolescent suicides? Suicide and Life-Threatening Behavior, 40(6), 609-611.

Kroenke, K., Spitzer, R. L., \& Williams, J. B. (2003). The patient health questionnaire-2: Validity of a two-item depression screener. Medical Care, 41(11), 1284-1292.

Lang, B. J., \& Lang, M. (2020). Firearm sales and the COVID-19 pandemic. SSRN Electronic Journal. https://doi.org/10.2139/ssrn. 3593956

Lang, B. J., \& Lang, M. (2021). Pandemics, protests, and firearms. American Journal of Health Economics, 7(2), 131-163.

Liu, G., \& Wiebe, D. J. (2019). A time-series analysis of firearm purchasing after mass shooting events in the United States. JAMA Network Open, 2(4), e191736-e191736.

Mann, J. J., Apter, A., Bertolote, J., Beautrais, A., Currier, D., Haas, A., Hegerl, U., Lonnqvist, J., Malone, K., \& Marusic, A. (2005). Suicide prevention strategies: A systematic review. JAMA, 294(16), 2064-2074.

Mannix, R., Lee, L. K., \& Fleegler, E. W. (2020). Coronavirus disease 2019 (COVID-19) and firearms in the United States: Will an epidemic of suicide follow? American College of Physicians., 173(3), 228-229.

Mazza, M., Marano, G., Lai, C., Janiri, L., \& Sani, G. (2020). Danger in danger: Interpersonal violence during COVID-19 quarantine. Psychiatry Research, 289, 113046. https://doi.org/10.1016/j.psych res.2020.113046

Miller, M., Azrael, D., Hemenway, D., \& Vriniotis, M. (2005). Firearm storage practices and rates of unintentional firearm deaths in the United States. Accident Analysis and Prevention, 37(4), 661-667.

Miller, M., Lippmann, S. J., Azrael, D., \& Hemenway, D. (2007). Household firearm ownership and rates of suicide across the 50
United States. Journal of Trauma and Acute Care Surgery, 62(4), 1029-1035.

Monuteaux, M. C., Azrael, D., \& Miller, M. (2019). Association of increased safe household firearm storage with firearm suicide and unintentional death among US youths. JAMA Pediatrics, 173(7), $657-662$.

Monuteaux, M. C., Lee, L. K., Hemenway, D., Mannix, R., \& Fleegler, E. W. (2015). Firearm ownership and violent crime in the US: An ecologic study. American Journal of Preventive Medicine, 49(2), 207-214.

Morgan, E. R., Gomez, A., \& Rowhani-Rahbar, A. (2018). Firearm ownership, storage practices, and suicide risk factors in Washington State, 2013-2016. American Journal of Public Health, 108(7), $882-888$.

Papadimos, T. J. (2020). What's new in critical illness and injury science? Mental health and COVID-19: Self-inflicted and interpersonal violence amid a pandemic. International Journal of Critical Illness and Injury Science, 10(2), 45.

Prickett, K. C., Martin-Storey, A., \& Crosnoe, R. (2014). State firearm laws, firearm ownership, and safety practices among families of preschool-aged children. American Journal of Public Health, 104(6), 1080-1086.

Reger, M. A., Stanley, I. H., \& Joiner, T. E. (2020). Suicide mortality and coronavirus disease 2019-A perfect storm? JAMA Psychiatry. https://doi.org/10.1001/jamapsychiatry.2020.1060

Richters, J., \& Saltzman, W. (1990). Survey of exposure to community violence: Self Report Version. Rockville, MD: National Institute of Mental Health.

Schleimer, J. P., McCort, C. D., Pear, V. A., Shev, A., Tomsich, E., AsifSattar, R., Buggs, S., Laqueur, H. S., \& Wintemute, G. J. (2020). Firearm purchasing and firearm violence in the first months of the coronavirus pandemic in the United States. MedRxiv. Pre-print https://doi.org/10.1101/2020.07.02.20145508

Sokol, R., Schmidt, C., Miller, A. L., Walton, M. A., Zimmerman, M., Resnicow, K., Cunningham, R. M., \& Carter, P. M. (2020). Motivations for firearm possession and storage practices among urban young adults: Differences between parents and non-parents. Injury Prevention.

Sorenson, S. B., \& Vittes, K. A. (2008). Mental health and firearms in community-based surveys: Implications for suicide prevention. Evaluation Review, 32(3), 239-256.

Straus, M. A., Hamby, S. L., Boney-McCoy, S., \& Sugarman, D. B. (1996). The revised conflict tactics scales (CTS2) development and preliminary psychometric data. Journal of Family Issues, 17(3), 283-316.

Usher, K., Bhullar, N., Durkin, J., Gyamfi, N., \& Jackson, D. (2020). Family violence and COVID-19: Increased vulnerability and reduced options for support. International Journal of Mental Health Nursing. https://doi.org/10.1111/inm.12735

Walton, M. A., Chermack, S. T., Shope, J. T., Bingham, C. R., Zimmerman, M. A., Blow, F. C., \& Cunningham, R. M. (2010). Effects of a brief intervention for reducing violence and alcohol misuse among adolescents: A randomized controlled trial. JAMA, 304(5), 527-535.

WISQARS. (2019a). Fatal Injury Reports, 2000-2019. Centers for Disease Control and Prevention, National Center for Injury Prevention and Control.

WISQARS. (2019b). Nonfatal Injury Reports, 2000-2017. Centers for Disease Control and Prevention, National Center for Injury Prevention and Control.

Publisher's Note Springer Nature remains neutral with regard to jurisdictional claims in published maps and institutional affiliations. 